Article

\title{
A Quantitative Morphological Method for Mapping Local Climate Types
}

\author{
Daniela Maiullari *, Marjolein Pijpers-van Esch and Arjan van Timmeren \\ Department of Urbanism, Delft University of Technology, The Netherlands; E-Mails: d.maiullari@tudelft.nl (D.M.), \\ m.m.e.pijpers-vanesch@tudelft.nl (M.P.-v.E.), a.vantimmeren@tudelft.nl (A.v.T.) \\ * Corresponding author
}

Submitted: 26 February 2021 | Accepted: 6 May 2021 | Published: 19 August 2021

\begin{abstract}
Morphological characteristics of cities significantly influence urban heat island intensities and thermal responses to heat waves. Form attributes such as density, compactness, and vegetation cover are commonly used to analyse the impact of urban morphology on overheating processes. However, the use of abstract large-scale classifications hinders a full understanding of the thermal trade-off between single buildings and their immediate surrounding microclimate. Without analytical tools able to capture the complexity of cities with a high resolution, the microspatial dimension of urban climate phenomena cannot be properly addressed. Therefore, this study develops a new method for numerical identification of types, based on geometrical characteristics of buildings and climate-related form attributes of their surroundings in a $25 \mathrm{~m}$ and $50 \mathrm{~m}$ radius. The method, applied to the city of Rotterdam, combines quantitative descriptors of urban form, mapping GIS procedures, and clustering techniques. The resulting typo-morphological classification is assessed by modelling temperature, wind, and humidity during a hot summer period, in ENVI-met. Significant correlations are found between the morphotypes' characteristics and local climate phenomena, highlighting the differences in performative potential between the classified urban patterns. The study suggests that the method can be used to provide insight into the systemic relations between buildings, their context, and the risk of overheating in different urban settings. Finally, the study highlights the relevance of advanced mapping and modelling tools to inform spatial planning and mitigation strategies to reduce the risk of urban overheating.
\end{abstract}

\section{Keywords}

data-driven classification; microclimate; typologies; urban morphology

\section{Issue}

This article is part of the issue "Smart Urban Governance for Climate Change Adaptation" edited by Thomas Thaler (University of Natural Resources and Life Sciences, Austria), Patrick Witte (Utrecht University, The Netherlands), Thomas Hartmann (TU Dortmund University, Germany) and Stan Geertman (Utrecht University, The Netherlands).

(C) 2021 by the authors; licensee Cogitatio (Lisbon, Portugal). This article is licensed under a Creative Commons Attribution 4.0 International License (CC BY).

\section{Introduction}

Urban planning research and practice are increasingly called to confront climate-related challenges of cities. While extreme events like heatwaves are becoming more frequent (Founda et al., 2019; Smid et al., 2019), climate scenarios also prognose an overall increase in temperatures in the coming decades (Guerreiro et al., 2018; Hoegh-Guldberg et al., 2018). Furthermore, climate change is expected to exacerbate warming mechanisms in urban environments already characterised by urban heat island (UHI) phenomena (Ward et al., 2016). At the same time, a growing number of European cities have active policies of urban (re-)densification (Næss et al., 2020; Westerink et al., 2013). Following the wellknown paradigm of compact and dense sustainable urban development (European Commission, 1991), this approach seems to mark a transition from a zoningoriented planning to an infill-planning that looks at local conditions for re-development (Amer et al., 2017; Wolff et al., 2017), increasing the morphological heterogeneity of the urban fabric (Marique \& Reiter, 2014) and giving 
rise to the so-called compact city paradox (Bibri et al., 2020). From a climate perspective, in fact, higher building densities generally increase the magnitude of UHI effects and overheating of cities (Oke, 1987).

Climate change and urban densification thus pose great challenges as well as opportunities for urban planning and design, with respect to developing new frameworks and strategies for the construction of climateresilient cities (Terrin, 2015). Although it is demonstrated that urban form characteristics significantly influence thermal and turbulent processes in cities, contributing to the formation of UHI effect (Oke et al., 1991), a deeper understanding of these processes in increasingly complex and heterogeneous built environments appears to be needed, in order to characterise the overheating risk at a finer scale-level and to facilitate the implementation of mitigation measures more sensitive to the local spatial conditions.

In the last decades, the field of urban climatology has been studying the role of urban form in urban climate phenomena, attempting to broaden the understanding of which spatial conditions exacerbate and reduce the risk of overheating (Zinzi \& Santamouris, 2019). Two distinct morphological approaches can be recognised. The first has mainly been employed in parametric and comparative studies, focusing on the investigation of single form attributes (Ali-Toudert \& Mayer, 2006; Morganti et al., 2017; Perini \& Magliocco, 2014). However, methods to quantitatively identify representative samples of existing urban tissues are largely lacking. This results in the common practice of qualitative selection of homogeneous or generic form patterns (Toparlar et al., 2017) that limits its use to guide design and planning in existing cities. The second morphological approach employs qualitative and quantitative descriptions of form attributes and supervised classification techniques in order to identify zones with similar climate characteristics. A wellknown representative of this approach is the local climate zone classification method (Stewart \& Oke, 2012) that supports the identification of regions of uniform land cover, material, structure, and anthropogenic activities, defining characteristic temperature regimes for 17 standard local climate zones. The "urban climate maps" resulting from these classifications have, until now, been considered a crucial basis to inform design and planning decisions (Lenzholzer, 2015) and are based on the concept that different types of urban areas have typical thermal behaviours. However, while these methods cover district to city scale, their large aggregative units result in a rather coarse classification unable to describe the level of heterogeneity of the urban fabric.

Advancements in the field of mathematical urban morphology (D'Acci, 2019) over the last 50 years may help overcome the limitations of the approaches in urban climatology discussed above. This branch of urban form studies focuses on the understanding of spatial structures and characteristics of urban areas through an empirical and quantitative approach. In particular, the typo-morphology body of research-traditionally interested in identifying qualitative comparable physical characteristics (Vernez Moudon, 1997)-is increasingly showing applications of quantitative methods for measuring (Berghauser Pont \& Haupt, 2010) and classifying urban forms (Serra et al., 2017). This recent typology-driven approach aims to overcome the use of traditional administrative units in the description of cities' physical context through morphological indicators (Serra et al., 2018), to support the application of typo-morphology to planning practice (Gil et al., 2012) and to facilitate the description of contemporary types that do not fall into standard classifications (Berghauser Pont et al., 2019).

Numerically defined typo-morphologies have been proposed in studies that have developed geocomputation methods for classifying forms of urban fabric and their basic physical elements: streets (Barthelemy, 2017), plots (Bobkova et al., 2019; Demetriou et al., 2013), buildings (Hecht et al., 2015; Perez et al., 2018), blocks (Peponis et al., 2007), and structural units (Haggag \& Ayad, 2002). Particularly relevant are the contributions of authors that have integrated geometrical multivariables and inter-scalar descriptions of urban form (Bobkova, 2019; Hausleitner \& Berghauser Pont, 2017; Serra et al., 2018) and have developed methodological strategies to identify potential links between contextual factors and other variables, generating context-informed samples of urban areas. A part of these multi-variables and inter-scalar studies has a strong focus on defining typologies to investigate the geographical distribution of types of urban fabric (Araldi \& Fusco, 2019) and to allow comparisons between cities (Berghauser Pont et al., 2019).

Despite the high potential of applying a typomorphology approach in climate-oriented studies, it nevertheless is still relatively unexplored. Thus, the aim of this article is to address the potentials of morpho-based classification systems as a complementary approach to those existing in urban climatology. In order to facilitate the understanding of how space at the microscale influences urban climate phenomena, this study proposes a data-driven morphological classification approach. This approach allows to address heterogeneous urban fabric by characterising buildings and their contextual conditions separately. In addition, it supports a better understanding of the impacts of form characteristics on patterns of thermal and aerodynamic behaviours.

This study focuses on the development of the approach and its application in the city of Rotterdam (the Netherlands). Section 2 of the article introduces the methodological framework (see Figure 1) to obtain and assess numerically defined typo-morphologies based on climate-related form attributes. In Section 3, the detailed methods to characterise urban form types are described and deployed in the Rotterdam case study. Section 4 presents the microclimate performance of the identified form types, modelled in ENVI-met. Finally, a comparison is carried out to analyse the variations in 
TYPO-MORPHOLOGY CLASSIFICATION

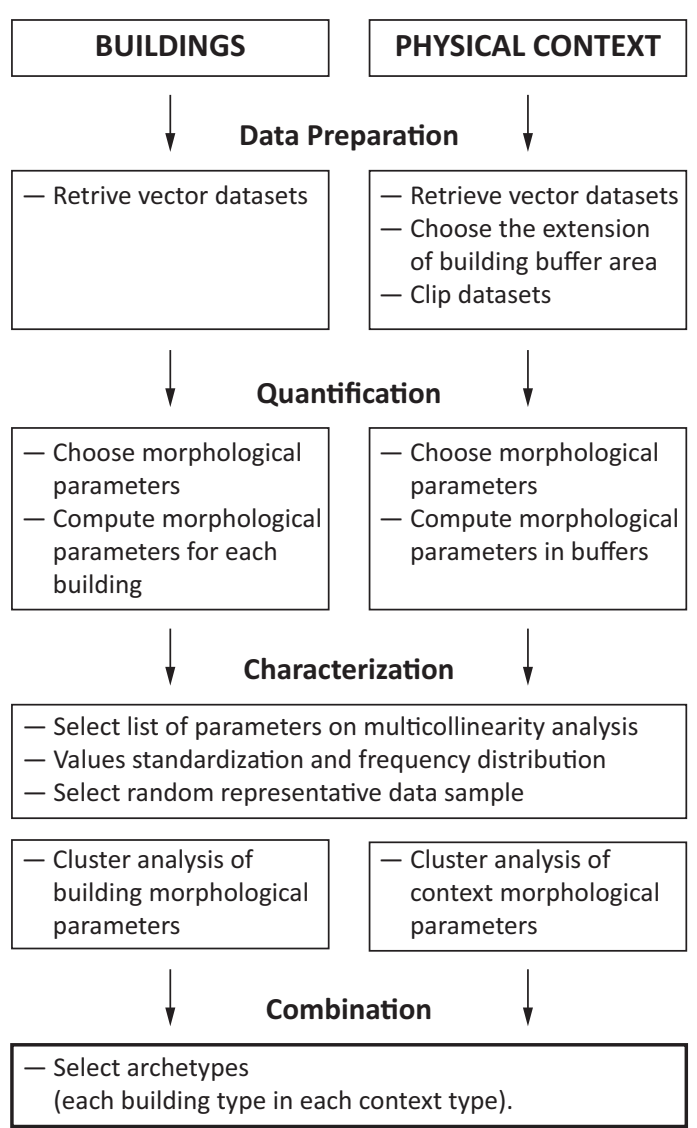

Figure 1. Methodological framework.

microclimate performance, dependent upon form characteristics of building types and context types, and conclusions are presented.

\section{Methodological Framework}

The proposed methodological framework builds on previous studies that integrate multi-variable geometrical descriptions with inter-scalar relational descriptions of urban form. To test the application of datadriven morphological classifications in the field of urban climatology, this study carries out a performance assessment on the identified typo-morphologies, by employing microclimate modelling. The methodological framework is therefore divided in two main parts: (1) typo-morphology classification, and (2) microclimate assessment, both organised in steps of data preparation, quantification, characterisation, and linked by a step named combination.

The methodology for the typo-morphology classification follows two parallel paths to identify building types and context types. Climate-related form attributes and measuring parameters are derived from literature and computed for buildings and context areas. The latter are defined by buffer areas from the buildings' envelopes, drawn with different radii. After combined statistical
MICROCLIMATE ASSESSMENT

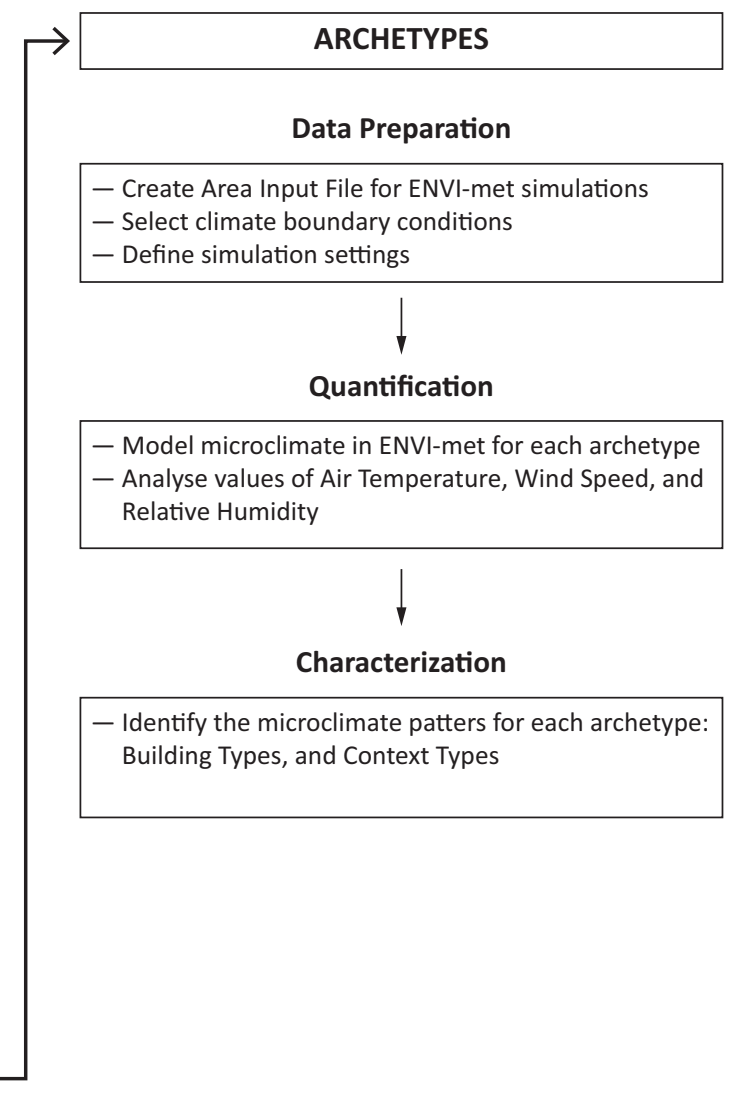

analyses on the calculated parameters, an unsupervised hierarchical clustering method is employed to identify and group similar objects (buildings) and similar surrounding conditions (contexts). After evaluating the optimal number of clusters, archetypical buildings for each context type are selected for the microclimate assessment phase.

This assessment is carried out through microclimate simulations in ENVI-met, a well-established urban climate model (Tsoka et al., 2018; Yang et al., 2013). Spatial vector-data of the domains under study is translated into 3D digital models and enriched with material attributes. Two hot summer days are selected as climate boundary conditions. After running the simulations, results for the selected archetypes are analysed by comparing air temperature, wind speed, and relative humidity values near building façades. Finally, microclimate patterns for the typo-morphologies and relations between building and context types are analysed.

\subsection{Case Study Description}

The methodological approach to identify and assess microclimate typo-morphologies is applied on the urban agglomeration of Rotterdam, the second largest city in the Netherlands, situated along the Nieuwe Maas 
river. The selection of this city allows for an analysis of the thermal performance of heterogeneous building and land cover configurations. Additionally, due to its densely built environment, Rotterdam has a significant UHI effect, as shown in previous studies (Roodenburg, 1983; Steeneveld et al., 2011). This urban climate phenomenon has a high intensity in the inner city and varies largely among urban districts. According to van Hove et al. (2015), atmospheric $\mathrm{UHI}_{\max }$ values in Rotterdam vary from $4.3^{\circ} \mathrm{C}$ to $8^{\circ} \mathrm{C}$ depending on local urban characteristics of different areas, while surface UHI values show a daytime magnitude of $10^{\circ} \mathrm{C}$, with a maximum variation in surface temperatures between warmest and coolest districts in a range of $12^{\circ} \mathrm{C}$ (Klok et al., 2012).

\section{Classification of Building and Context Types}

The overall goal of this classification is to identify typo-morphologies through clustering of climate-related urban form parameters for the city of Rotterdam. Usually, in both planning research and practice, urban form parameters are measured at large predefined units (administrative or dependent upon land ownership) that are biased by a high level of aggregation (Serra et al., 2018). The proposed framework overcomes this bias by allowing for the separate identification of building and context types. This approach is expected to allow for a distinction between microclimate behaviour that depends on a building's surroundings, from that which depends on the building's own geometrical characteristics.

\subsection{Data Preparation for Morphological Quantification}

The spatial datasets used in this study were made available by the Municipality of Rotterdam, and contain information regarding buildings, street network, vegetation cover, and trees at their status in December 2018. For the building dataset, data processing was necessary to extract basic geometrical characteristics from a 3D city model. Building footprints and heights were derived from the available 3D digital model in CityGML format (Gemeente Rotterdam, 2018). The term "building" here indicates a basic unit characterised by a singular height, that can also correspond to building parts in the case of complex geometries. Regarding the context data, two extra steps of refinement were required. First, buffer areas around each building were defined, with 25 and $50 \mathrm{~m}$ radius, calculated from the building envelope. These radii have proven adequate to observe variations in microclimate processes (Jin et al., 2018; Takebayashi, 2017) as in these areas around the building the form characteristics of the tangent street canyons $(25 \mathrm{~m})$ and the surrounding district structure $(50 \mathrm{~m})$ are captured. Second, the datasets for each buffer were clipped to facilitate the computation of morphological parameters within these areas in the next phase.

\subsection{Quantification of Morphological Attributes}

In order to quantitatively describe the geometry of buildings and the form of the urban fabric, a set of eight climate-related morphological parameters was selected. The parameters chosen, based on literature, are quantitative and morphological by nature. The selection followed four main criteria; the parameters (1) describe attributes that influence the thermal behaviour of buildings and microclimate processes in their surroundings, (2) have minimal redundancy, (3) can be easily understood by planners and designers, and (4) are easily calculated.

For the building characterisation, three parameters were considered: height, footprint, and surface-tovolume ratio. Building height (B_Height) expresses the vertical dimension of a building object. From a microclimate perspective, wind speed and turbulence exponentially increase with increasing B_Height, while air temperature tends to decrease further from the ground. Building footprint (B_Footprint) describes the horizontal occupation of the buildings at the ground. The size of the footprint correlates with potential solar accessibility. Surface-to-volume ratio (B_StoV) measures the proportion between the exposed building envelope and its volume. The larger the value of B_StoV, the lower the compactness level. From a climate design perspective this parameter captures radiation accessibility and ventilation potential, mediated by the interface between outdoor and indoor environments (Vartholomaios, 2017).

In addition, five variables were used to measure urban fabric attributes of roughness, density, and green coverage, describing the morphological characteristics of the buildings' context. Mean building height (MeanH) is a primary descriptor of roughness. The roughness of the urban surface defines the friction capacity of the built environment to aerodynamic processes (Grimmond \& Oke, 1999). MeanH identifies the average height of the context in a buffer of $50 \mathrm{~m}$ radius. Floor space index (FSI) and ground space index (GSI; Berghauser Pont \& Haupt, 2010) are two of the most known density indicators that describe the intensity of built space and building coverage, influencing the magnitude of overheating (Zhao et al., 2016) and solar irradiance (Morganti et al., 2017). FSI is defined as the ratio of the gross floor area to the overall site surface, which is calculated in the larger buffer area to describe the level of fabric compactness around a building. GSI is calculated as the ratio of buildings' footprint to the overall site surface. In this study, GSI (calculated in a $25 \mathrm{~m}$ radius buffer) is used to intercept the closeness of buildings in the immediate surrounding. Vegetation cover affects microclimate in urban environments, by influencing air temperatures through shading and evapotranspiration, and by modifying wind velocity (Duarte et al., 2015; Perini \& Magliocco, 2014). Two parameters are chosen to measure greenery characteristics. Green area (GArea) measures the total green coverage of grass surfaces in the larger buffer area $(50 \mathrm{~m})$, 
while tree area (TArea) measures the sum of tree crown area in the smaller buffer area $(25 \mathrm{~m})$. The list of morphological parameters used to describe building and context form is shown in Table 1 . The eight variables deployed were computed for over 150,000 buildings and related buffer areas through the QGIS programme.

\subsection{Urban Form Characterisation}

All calculated morphological variables were standardised as z-scores in order to have similar scales. Since multi-collinearity should be avoided for unsupervised classification (Tan et al., 2005), a screening was performed to detect potential collinearity, confirming that the selected eight variables were not correlated.

In order to classify building and context characteristics a hierarchical cluster analysis was used. The hierarchical cluster analysis is an unsupervised classification method that groups data into homogeneous classes by proceeding stages. Beginning by defining each observation as a cluster, clusters get incrementally paired based on the minimum distance between them, until the merging of all values results in a single cluster. Although k-mean clustering has a stronger applicability to large datasets, the explorative character of the study required a certain degree of flexibility. From this perspective, hierarchical clustering would allow for the identification of the hierarchical relation between classes and provide the possibility to read the microclimate assessment results at different cutting levels of the dendrogram. Thus, to allow the applicability of a hierarchical cluster analysis despite computational restrictions, a representative $20 \%$ sample of the full data population was selected. A KolmogorovSmirnov test verified that the sample was statistically significant and preserved the same probability distribution of the full dataset.

The three building and five context variables calculated for the 21,047 features of the sample were

Table 1. Summary of the selected morphological parameters.

\begin{tabular}{|c|c|c|c|c|}
\hline Categories & Unit & Parameter/Variable & Description & Sources \\
\hline \multirow[t]{3}{*}{$\begin{array}{l}\text { Building } \\
\text { Geometry }\end{array}$} & Building parts & B_Height (m) & Measure of the B_Height & $\begin{array}{l}\text { Godoy-Shimizu et al., 2018; } \\
\text { Jurelionis \& Bouris, 2016; } \\
\text { Mangan et al., 2021; } \\
\text { Saroglou et al., 2017; } \\
\text { Yunhao Chen et al., } 2020\end{array}$ \\
\hline & & B_Footprint $\left(\mathrm{m}^{2}\right)$ & Area of the B_Footprint & $\begin{array}{l}\text { Allen-Dumas et al., 2020; } \\
\text { Hecht et al., 2015; } \\
\text { Mavrogianni et al., 2012; } \\
\text { Yixing Chen et al., } 2019\end{array}$ \\
\hline & & B_StoV $\left(\mathrm{m}^{2} / \mathrm{m}^{3}\right)$ & $\begin{array}{l}\text { Building envelope to } \\
\text { volume ratio }\end{array}$ & $\begin{array}{l}\text { Bourdic et al., 2012; Caldera } \\
\text { et al., 2008; Mashhoodi } \\
\text { et al., 2020; Ratti et al., } \\
\text { 2005; Salat, } 2009\end{array}$ \\
\hline
\end{tabular}

$\begin{array}{llll}\text { Context } & \text { Buffer } & \text { GSI } & \text { GSI } \\ \text { Morphology } & 25 m \text { radius } & & \end{array}$

Morphology $25 m$ radius

TArea $\left(\mathrm{m}^{2}\right)$

Buffer

FSI

$50 \mathrm{~m}$ radius

MeanH $\left(\mathrm{m}^{2}\right)$

GArea $\left(\mathrm{m}^{2}\right)$
Total grass coverage area in buffer
Average B_Height in buffer

Salvati et al., 2020

Touchaei \& Wang, 2015;

Wang et al., 2017

Kong et al., 2016; Lobaccaro

\& Acero, 2015; Skelhorn

et al., 2014; Vaz Monteiro

et al., 2016; Wu et al., 2019 
separately processed using a hierarchical cluster analysis with application of Ward's minimum variance method. To select the optimal number of clusters, the resulting dendrograms for the building classification and context classification were analysed (Figure 2). The cutting level was selected where the linking vertical lines are long(est) and the smallest number of clusters distinguishes sufficient differences among the groups. Thus, for both building and context variables, the optimal division is a fivecluster solution. Plotting the parameter values per cluster and a visual inspection of the cluster-centroids confirmed clear differences between the five building types, as well as between the five context types.

\subsubsection{Description of the Building and Context Types}

The combination of the selected morphological characteristics produced consistent typo-morphologies. The plotting and numeric profiling of the building and context types is shown in Figure 3. Building types identified through clustering of B_Height, B_Footprint, and B_StoV parameters can be described based on Figure 4.

B_Type1 and B_Type3 are low-rise buildings with a very small B_Footprint. The main difference between them is the level of compactness. Buildings of type 1 have a low compactness level (high StoV ratio), while buildings of type 3 have a high compactness level (low StoV ratio). These types predominately comprise of single houses, rowhouses, and small building parts. B_Type2 and $B$ _Type 5 consist of highly compact mid-rise buildings (low StoV). The discriminant between the two groups is the ground coverage size. While buildings in type 2 are characterised by small footprints (slabs, apartment buildings), in type 5 the B_Footprints are the largest, comprising of public facilities and industrial/commercial objects with a horizontal volume distribution. B_Type4 is composed of high-rise buildings with a medium size footprint and a high level of compactness (low StoV ratio). Towers and tall building parts on plinths belong to this group.

Context types emerged from the clustering analysis of GSI and TArea ( $25 \mathrm{~m}$ buffer), and FSI, MeanH, and GArea (50m buffer). According to Figures 3 and 4 , the types can be described as follows:
- C_Type1 consists mainly of low and mid-rise urban fabrics, with low density characteristics (low GSI and $\mathrm{FSI}$ ). The main defining characteristic is the very large tree crown area and the medium level of grass coverage. This type of context tissue shows the ample presence of trees mainly located along street canyons.

- C_Type2 is characterised by mid-rise buildings, and medium density in terms of building coverage (GSI) and built-up intensity (FSI). The type has low values of grass and tree coverage.

- C_Type3 and C_Type4 are urban tissues both defined by low-rise buildings and low density. The main difference between the two types is the quantity of grass surfaces, which is very low in type 3 and medium in type 4.

- Finally, C_Type5 can be described by highly compact conditions of the urban fabric, characterised by high-rise, high building intensity, and building coverage. In this context type, greenery level (TArea, GArea) is low.

\subsection{Archetype Selection}

Once building types and context types were characterised and semantically described, 25 "archetypes" were selected to analyse the microclimate profile of the five building types in the five context conditions. Usually, the archetype is defined as the case that is closer to the cluster's centroid. Therefore, five cases were selected close to the cluster's centroid for each building type, one case for each context type (Figure 5).

\section{Microclimate Assessment}

Microclimate simulations of the 25 archetypes were performed with ENVI-met 4.4. ENVI-met is a threedimensional prognostic model able to simulate the interaction between air, vegetation, and surfaces within an urban environment (Bruse \& Fleer, 1998). This holistic microclimate modelling tool is widely used to compute air and surface temperatures, turbulence, radiation fluxes, humidity, and evaporation fluxes (Tsoka et al.,

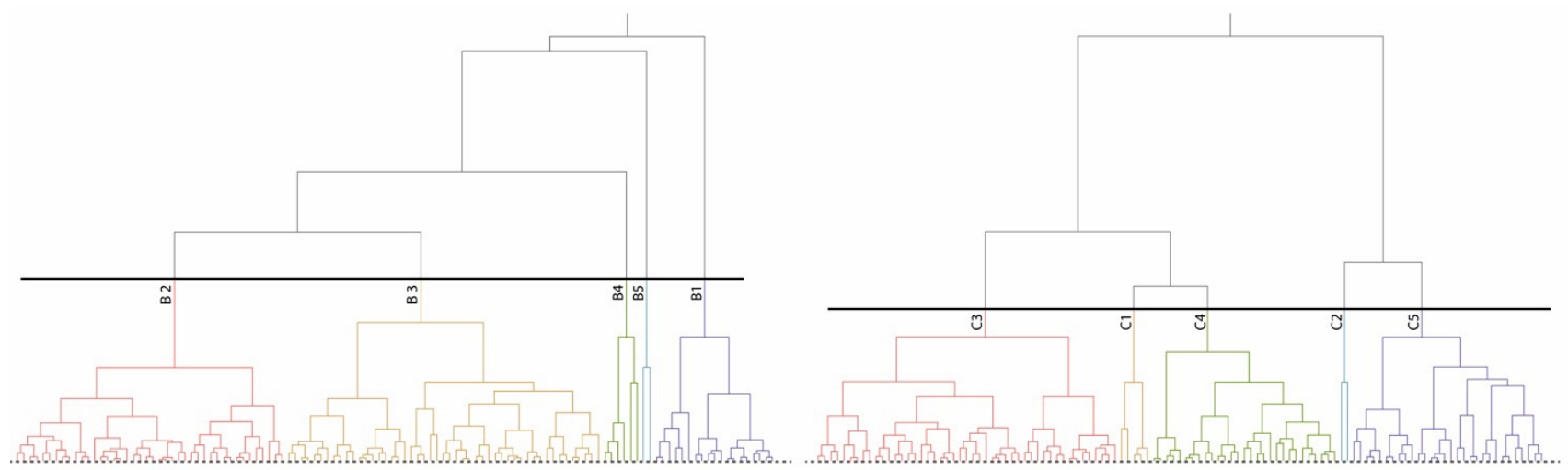

Figure 2. Hierarchical classification. Results: Building types (left) and context types (right). 

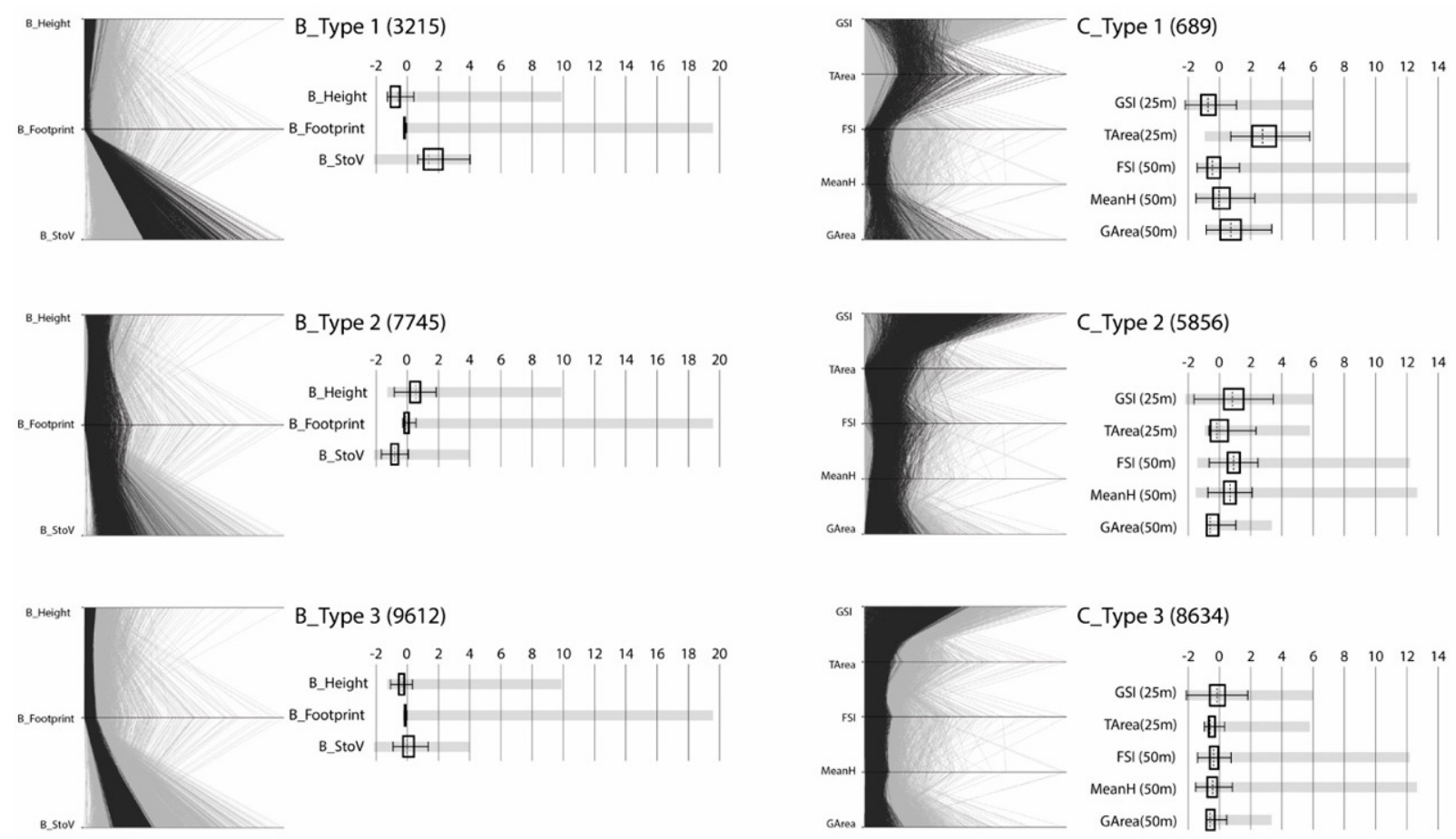

C_Type 3 (8634)
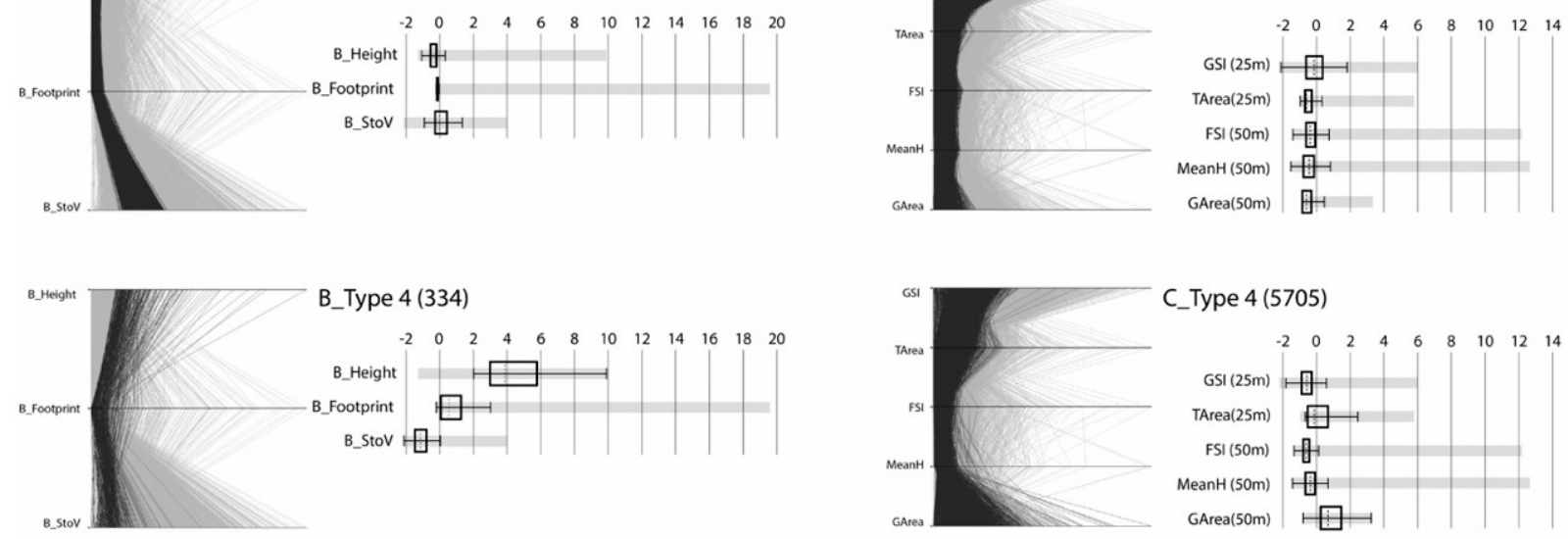

C_Type 4 (5705)
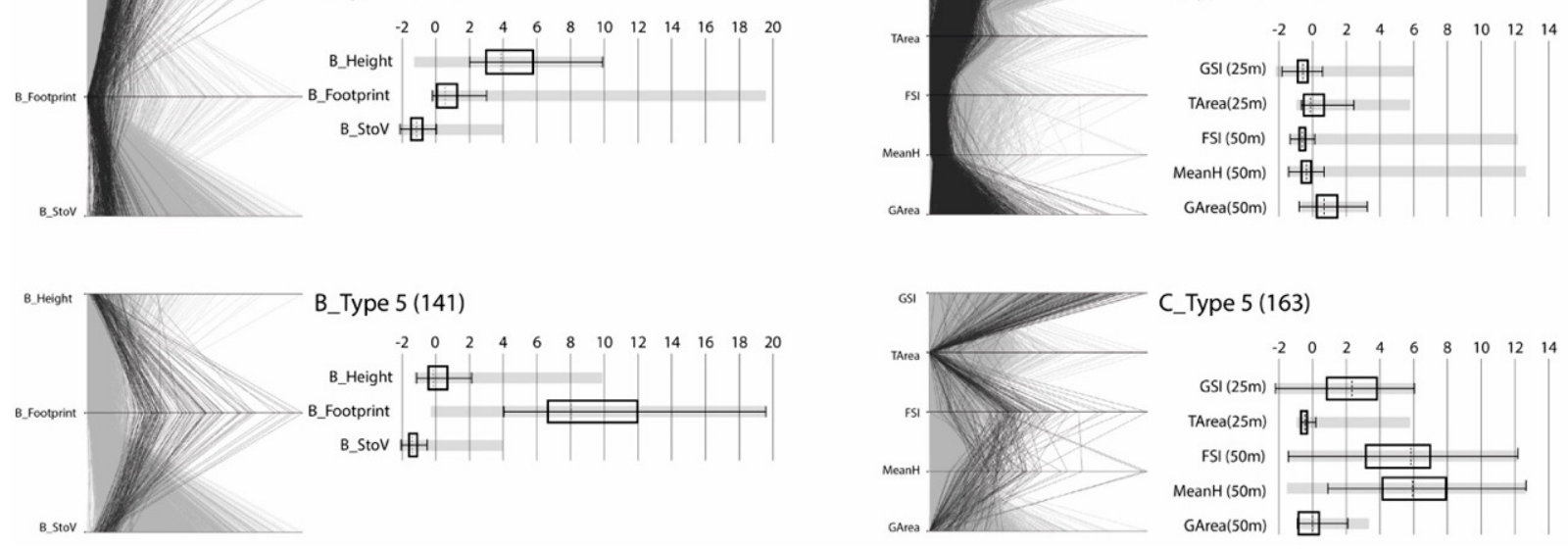

Figure 3. Standardised (z-score) numerical profiles of the building types (left column) and context types (right column).

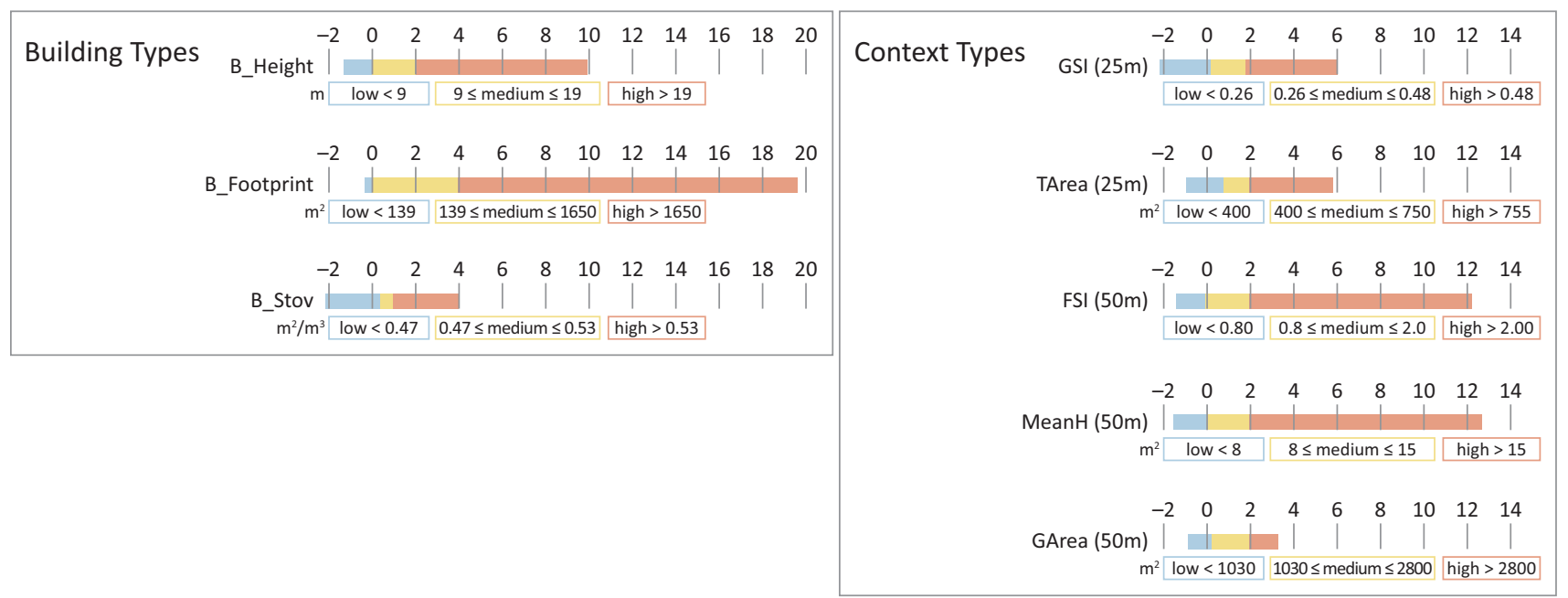

Figure 4. Numerical thresholds for the description of the building types (left) and context types (right). 


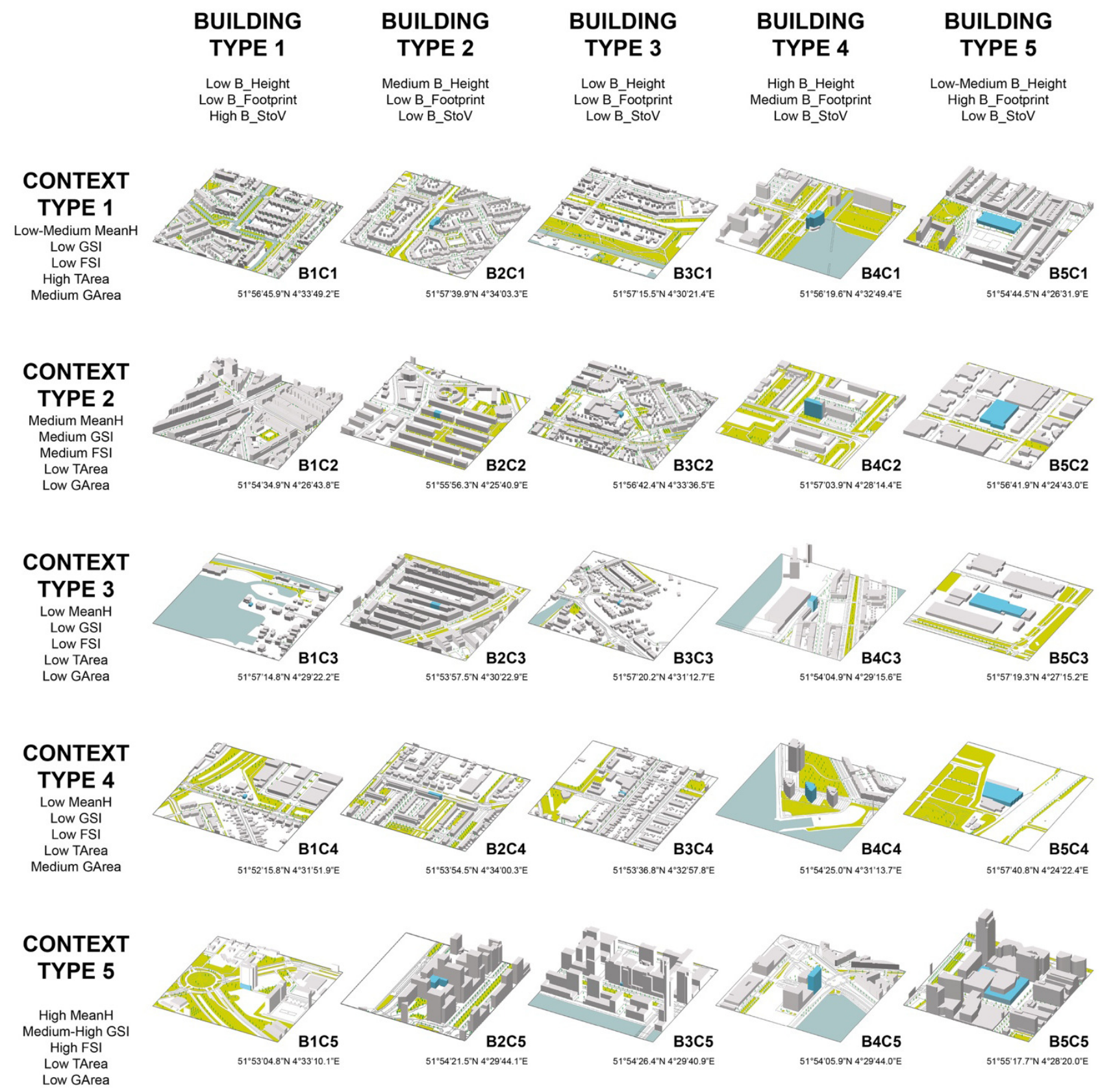

Figure 5. Visualisation of the building archetypes in the five context types.

2018). Validation studies have confirmed its high level of accuracy in modelling microclimate processes in urban conditions (Crank et al., 2018; Salata et al., 2016), and a high sensitivity to morphological characteristics of the built environment (Forouzandeh, 2018).

\subsection{Data Preparation for Microclimate Modelling}

To perform an ENVI-met simulation three types of input are required:

1) Digital spatial model: In the area input files, the model domains were created using a grid cell unit of $3 m(x)$ by $3 m(y)$ by $3 m(z)$. In these domains, the
3D models were built using the Rotterdam dataset in shape format through the ENVI-met submodule Monde. To be able to isolate the microclimate impact of morphological factors, material characteristics were kept constant in all 25 models.

2) Material database: Three surface materials (asphalt for roads, concrete bricks for other paved surfaces, and grass for unpaved areas) were derived from ENVI-met default database, and a fourth-a theoretical building wall with medium insulation properties-was created in the user database. Additionally, based on height and crown diameter, trees were classified into three categories (small, medium, large). 
3) Simulation settings: ENVI-met simulations used the full forcing method, by employing KNMI data from the weather station at Rotterdam Airport. After analysing the measured data of the past 10 years, two consecutive hot days $\left(T_{\max }>24^{\circ} \mathrm{C}\right)$ were selected by filtering out days with clouds and rain. The two days identified therefore meet the required conditions for microclimate simulations. The first day (29 June 2018), a maximum air temperature of $25^{\circ} \mathrm{C}$ was reached, while on the second day (30 June 2018), it reached up to $28^{\circ} \mathrm{C}$.

Before performing the simulations for the different archetypes a validation procedure was carried out. The existing urban areas around the urban weather stations of Delfshaven and Ommoord in Rotterdam were modelled with the material and meteorological settings described above. The ENVI-met spatial models of these two areas were built including the $50 \mathrm{~m}$ buffer area around the building on which the sensors are positioned, in other words, with a domain size defined as for the archetypes. The comparison between model results and measured temperature values (TU Delft, 2018) showed an index of agreement (Willmott, 1982) of 0.98, confirming the good accuracy of ENVI-met and the reliability of the input data.

\subsection{Microclimate Quantification Results and Discussions}

The cumulative microclimate performance of the Rotterdam cases was analysed by comparing the rural climate conditions to the simulation results (Figure 6). Air temperature, wind speed and relative humidity values were retrieved in the air layer near the façades. Values were averaged for each building archetype. The comparison between simulated air temperatures and measured data at the rural KNMI weather station shows a clear UHI effect, in particular during daytime, for both days. The 25 simulated areas are generally warmer than the rural environment with an average maximum UHI effect of $1.1^{\circ} \mathrm{C}$. The maximum UHI effect occurs between 12:00 and 15:00, and ranges between $0.5^{\circ} \mathrm{C}$ (B4C5) and $3^{\circ} \mathrm{C}$ (B1C4 and B3C2). The nocturnal UHI shows a smaller magnitude, reaching up to a maximum effect of $0.5^{\circ} \mathrm{C}$.

Another clear effect is the decrease in wind speed. During the two days under study, wind velocity at the rural station reached $6 \mathrm{~m} / \mathrm{s}$ during daytime, with a significant drop during night-time. Compared to the rural hinterland conditions, the modelling results show that the overall urban wind velocity decreases strongly, down to $1 \mathrm{~m} / \mathrm{s}$ on average.

Relative humidity values, plotted in Figure 6, illustrate that during night-hours, humidity values reach a $\mathrm{RH}$ of $95 \%$ while during day-hours it drops below $30 \%$ for the second hot day. Compared to the values at the rural weather station, the humidity values in the urban samples from Rotterdam decrease within a maximum of $7 \%$, which is consistent with observations in other studies (Ackerman, 1987; Liu et al., 2009). During daytime, the $\mathrm{RH}$ in the city is lower than in the rural hinterland, which can be correlated to the occurrence of the UHI effect.

This analysis of the simulation results also highlights the magnitude of microclimate variations for the Rotterdam sample of 25 archetypes. Since materials and settings were kept constant in the modelling process, it could be argued that the microclimate variations analysed are mainly dependent on morphological characteristics. The observed maximum differences in air
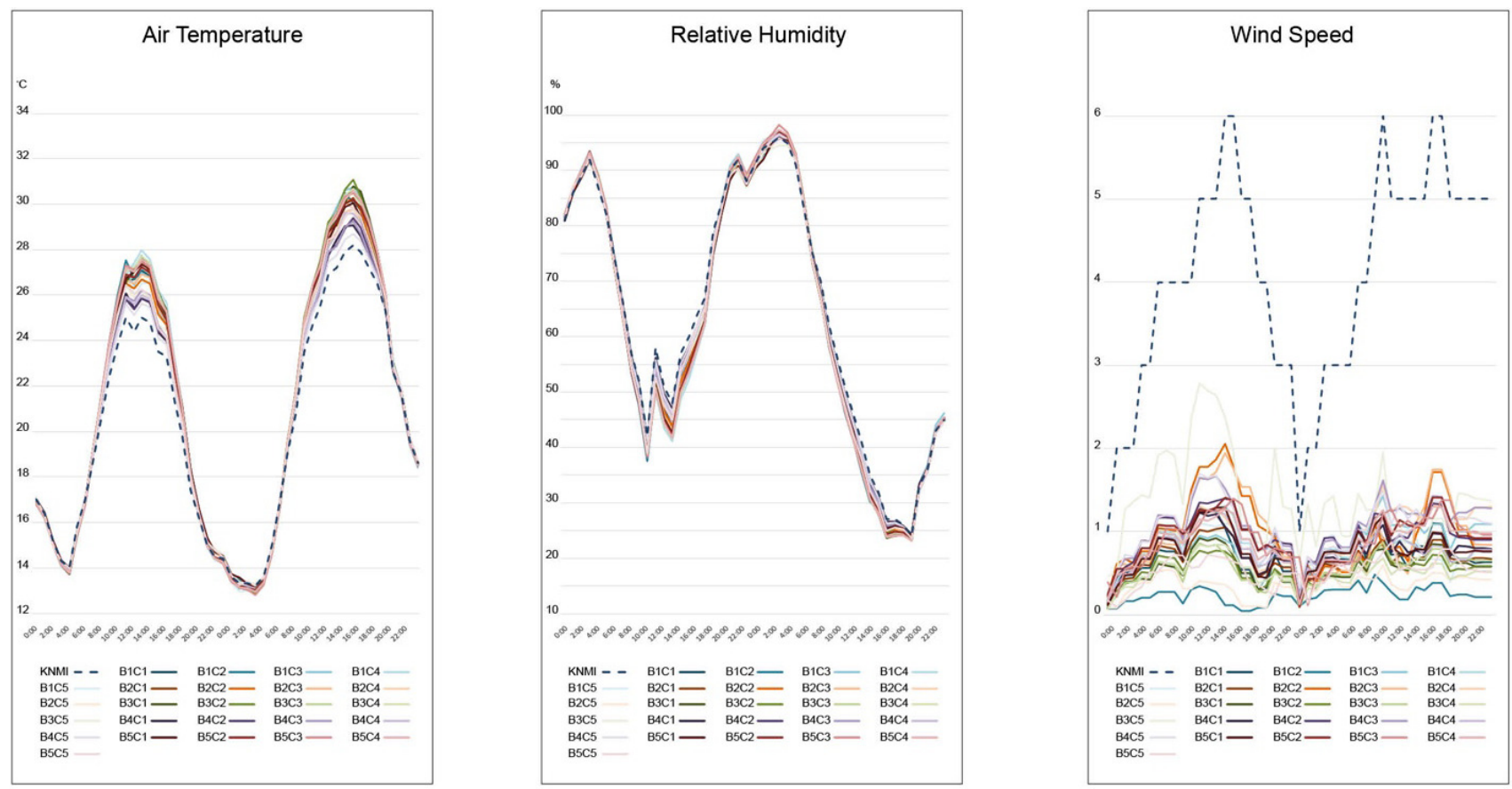

Figure 6. Building average air temperature (left), relative humidity (centre), and wind speed (right) near façade. 
temperature, humidity, and wind among the 25 cases suggest that building geometry and urban form of the context account for up to $2.5^{\circ} \mathrm{C}$ change in air temperature, up to $3 \mathrm{~m} / \mathrm{s}$ change in wind speed, and up to $5 \%$ change in relative humidity.

As stated, the models' results indicate that, during the two days under study, the $\mathrm{UHI}$ intensity reaches $3^{\circ} \mathrm{C}$. However, previous studies have found stronger magnitudes (between 2.3 and $8.0^{\circ} \mathrm{C}$ ) during day- and especially night-time in Rotterdam (Steeneveld et al., 2011; van Hove et al., 2015). These studies are based on field measurements, and therefore also include anthropogenic heat and its contribution to the energy balance; ENVI-met does not. As it was the objective of this study to assess the impact of solely morphology on UHI, the omission of anthropogenic heat is justified, but is expected to lead to an underestimation of the UHI effect. Furthermore, for the same reason of isolating morphological effects, the 25 models in this study had greatly simplified building and paving material characteristics, which may also have influenced the magnitude of the modelled UHI.

\subsection{Characterisation of Microclimate Patterns in Types}

In order to understand if the typo-morphologies have typical thermal and aerodynamic behaviour, climate patterns are analysed for each building and context type. Furthermore, the overall capability of the datadriven classification in identifying common climate conditions based on morphological characteristics is assessed. Simulation results are retrieved for indoor air temperature as well as outdoor air temperature and wind speed near the façade and averaged for each building.

\subsubsection{Indoor Temperature Patterns for the Different Building Types}

The analysis of indoor temperatures highlights common behaviour for the different building types (Figure 7). In particular, low-rise buildings (B_Type 1 and 3) demonstrate a larger sensitivity to the influence of context. Low rise buildings in high-rise contexts (B1C5 and $\mathrm{B} 3 \mathrm{C} 5$ ) yield the lowest indoor temperature among the 25 cases, due to reduced solar access at the façade. Except for these two "outliers," the cases representing each building type show similar thermal patterns. Therefore, each type can be described by the characteristic variation range between its five cases and the maximum temperature.
As shown in Table 2, B_Type4 has the lowest temperature variation among its cases, followed by B_Type 3,5 , and 1 . The highest variation is registered among B_Type2 cases. The similar behaviour among cases belonging to the same building type indicates that the context has a limited effect on the indoor temperature: The smaller the variation among cases, the lower the sensitivity of the building type to the context. Thus, high-rise buildings are the least affected by the surrounding conditions, while mid-rise buildings with low coverage are most influenced by their context.

$T_{\max }$ is higher in B_Type1 than in B_Type2, 5, and 3. High-rise buildings (B_Type4) consistently yield cooler indoor thermal conditions than the other building types. This is due to the lower contribution of radiation to the total thermal budget of the building due to the higher volumetric size, the higher exposure to cooling wind flows, and the fact that outdoor air temperatures tend to be lower when further away from the ground level.

\subsubsection{Wind Speed Patterns for the Different Building Types}

Wind velocity regulates heat dispersion from built surfaces and is strongly influenced by individual buildings and the roughness of their surroundings. As shown in Figure 7, the five cases of each building type experience similar wind speed behaviour near the façades. However, some exceptions can be observed for buildings in medium and highly dense contexts (B1C2, B3C5, and $\mathrm{B} 5 \mathrm{C5}$ ), which according to the size of the surrounding street canyon have very high or very low wind speed values.

All B_Type3, except for B3C5, show the lowest values of wind velocity (Table 3 ), with $U_{\max }$ below $0.8 \mathrm{~m} / \mathrm{s}$ and a limited maximum variation among context types $(0.3 \mathrm{~m} / \mathrm{s})$. It is followed by B_Type1 (except B1C2) and B_Type 5 (except B5C5), which have a medium wind velocity near the façade (reaching an $U_{\max }$ of $1.4 \mathrm{~m} / \mathrm{s}$ ). The variation among cases accounts for $0.5 \mathrm{~m} / \mathrm{s}$. B_Type 4 is the building type that shows higher values of wind speed $\left(U_{\max }=1.75 \mathrm{~m} / \mathrm{s}\right)$, with a slightly higher interval among cases $(0.6 \mathrm{~m} / \mathrm{s})$. B_Type 2 shows quite different characteristics, as a clear pattern could not be identified. The latter type is characterised by medium height and a small footprint area and seems to be more sensitive to the size and predominant direction of the street canyons in the immediate surroundings.

Table 2. Patterns of indoor temperatures per building type.

\begin{tabular}{llllll}
\hline Indoor Temperature & B_Type1 & B_Type2 & B_Type3 & B_Type4 & B_Type5 \\
\hline Variation among cases & $1^{\circ} \mathrm{C}(\mathrm{B} 1 \mathrm{C} 1-\mathrm{B} 1 \mathrm{C} 4)$ & $1.3^{\circ} \mathrm{C}$ & $0.4^{\circ} \mathrm{C}$ (B1C1-B1C4) & $0.2^{\circ} \mathrm{C}$ & $0.6^{\circ} \mathrm{C}$ \\
Maximum temperature & $25.2^{\circ} \mathrm{C}(\mathrm{B} 1 \mathrm{C} 1-\mathrm{B} 1 \mathrm{C} 4)$ & $24.6^{\circ} \mathrm{C}$ & $24.8^{\circ} \mathrm{C}(\mathrm{B} 1 \mathrm{C} 1-\mathrm{B} 1 \mathrm{C} 4)$ & $23.2^{\circ} \mathrm{C}$ & $24.6^{\circ} \mathrm{C}$ \\
Outliers & $\mathrm{B} 1 \mathrm{C} 5$ & & $\mathrm{~B} 3 \mathrm{C} 5$ & \\
\hline
\end{tabular}


Table 3. Patterns of wind speed per building type.

\begin{tabular}{|c|c|c|c|c|c|}
\hline Wind Speed & B_Type1 & B_Type2 & B_Type3 & B_Type4 & B_Type5 \\
\hline Variation among cases & $0.5 \mathrm{~m} / \mathrm{s}(\mathrm{B} 1 \mathrm{C} 1-\mathrm{C} 3-\mathrm{C} 4-\mathrm{C} 5)$ & $1.5 \mathrm{~m} / \mathrm{s}$ & $0.3 \mathrm{~m} / \mathrm{s}(\mathrm{B} 1 \mathrm{C} 1-\mathrm{B} 1 \mathrm{C} 4)$ & $0.6 \mathrm{~m} / \mathrm{s}$ & $0.5 \mathrm{~m} / \mathrm{s}$ \\
\hline Maximum speed & $1.4 \mathrm{~m} / \mathrm{s}$ & $2 \mathrm{~m} / \mathrm{s}$ & $0.8 \mathrm{~m} / \mathrm{s}$ & $1.75 \mathrm{~m} / \mathrm{s}$ & $1.4 \mathrm{~m} / \mathrm{s}$ \\
\hline Outliers & $\mathrm{B} 1 \mathrm{C} 2$ & & B3C5 & & B5C5 \\
\hline
\end{tabular}

\subsubsection{Air Temperature Patterns for Different Context Types}

In Figure 7, hourly values of the five cases per context type are plotted. Data clearly show that, independently of the context, temperatures are always the lowest around high-rise buildings (B_Type4). Inversely, the other four building types all together respond in a similar way to the context conditions (Figure7).

In group C_Type1, C_Type3, and C_Type4, having a low level of built-up intensity (FSI) and coverage (GSI) in common, but differing in grass and tree coverage, $\mathrm{T}_{\max }$ values are similar, ranging from $29.8^{\circ} \mathrm{C}$ to $30.6^{\circ} \mathrm{C}$, the second day. $T_{\max }$ variation among cases accounts for a $0.8^{\circ} \mathrm{C}$ (Table 4). The results suggest that at the microscale, vegetation has a minor effect on heat mitigation in contexts of low building density.

In C_Type2, characterised by a mid-rise context at medium density, high air temperatures and overall larger variations are observed. The fact that more variation exists among buildings in this context indicates a stronger trade-off between building geometry and mid-rise context at medium density. This can be explained by the fact that shading caused by the surroundings increases with the incline of height and compactness. Moreover, the influence of shading from the same context has a bigger impact on low-rise buildings than on higher ones. C_Type5 is the context with the most evident influence pattern on air temperatures. The high-density and highrise characteristics that define this context type contribute to keeping daytime temperature for all the building types below $30^{\circ} \mathrm{C}$ on the second day. Compared to the other contexts, here air temperatures are the lowest during daytime hours and the highest during night-time hours.

The very similar behaviours of C_Type1, 3, and 4 suggest that while the three types characterise different urban fabric conditions, from a climatic perspective they correspond to similar temperature patterns. Observing the dendrogram (Figure 2) and the hierarchical relations between types, it can be noted that these three groups merge at the upper level in one type.

\section{Limitations}

As shown in this study, data-driven classifications offer a novel methodological approach in urban climatological mapping, able to address the complexity and heterogeneity of urban environments. The characterisation of types and microclimate assessment carried out in this study are subject to several limitations.

For the types' characterisation, climate-related morphological parameters were derived from literature. These well-established parameters describe attributes of size and compactness for single buildings, and density, roughness, and green coverage for urban fabrics. However, a more extensive list of parameters can be found in literature. Among others, characteristics of building orientation, window-to-wall ratio, sky view factor, fabric porosity, and water coverage have shown to influence thermal and aerodynamic processes. Despite the undeniable benefits of enlarging the number of variables to better characterise the types, this would result in an exponential increase of data preprocessing and multidimensional clustering computation. Therefore, the authors have chosen the parameters most relevant for the method and case study at hand.

Regarding microclimate modelling, although the heat produced by anthropogenic activities (mobility, space heating and cooling, industry) is an important component in the energy balance of urban environments, ENVI-met is not able to model the thermal contribution of these activities. Additionally, in the modelling of the archetypes, material of buildings and street surfaces are assumed to have similar characteristics for all 25 cases. Even though ENVI-met allows to define individual surface

Table 4. Patterns of outdoor air temperature per context type.

\begin{tabular}{llllll}
\hline Air Temperature & C_Type1 & C_Type2 & C_Type3 & C_Type4 & C_Type5 \\
\hline Variation & 0.8 & 1 & 0.8 & 0.8 & 0.8 \\
among cases & (B1C1-C2-C3-C5) & (B1C1-C2-C3-C5) & (B1C1-C2-C3-C5) & (B1C1-C2-C3-C5) & (B1C1-C2-C3-C5) \\
$\begin{array}{l}\text { Maximum } \\
\text { temperature }\end{array}$ & 30.8 & 31.1 & 30.7 & 30.8 & 29.9 \\
Outliers & B1C4 & B2C4 & B3C4 & B4C4 & B5C4 \\
\hline
\end{tabular}



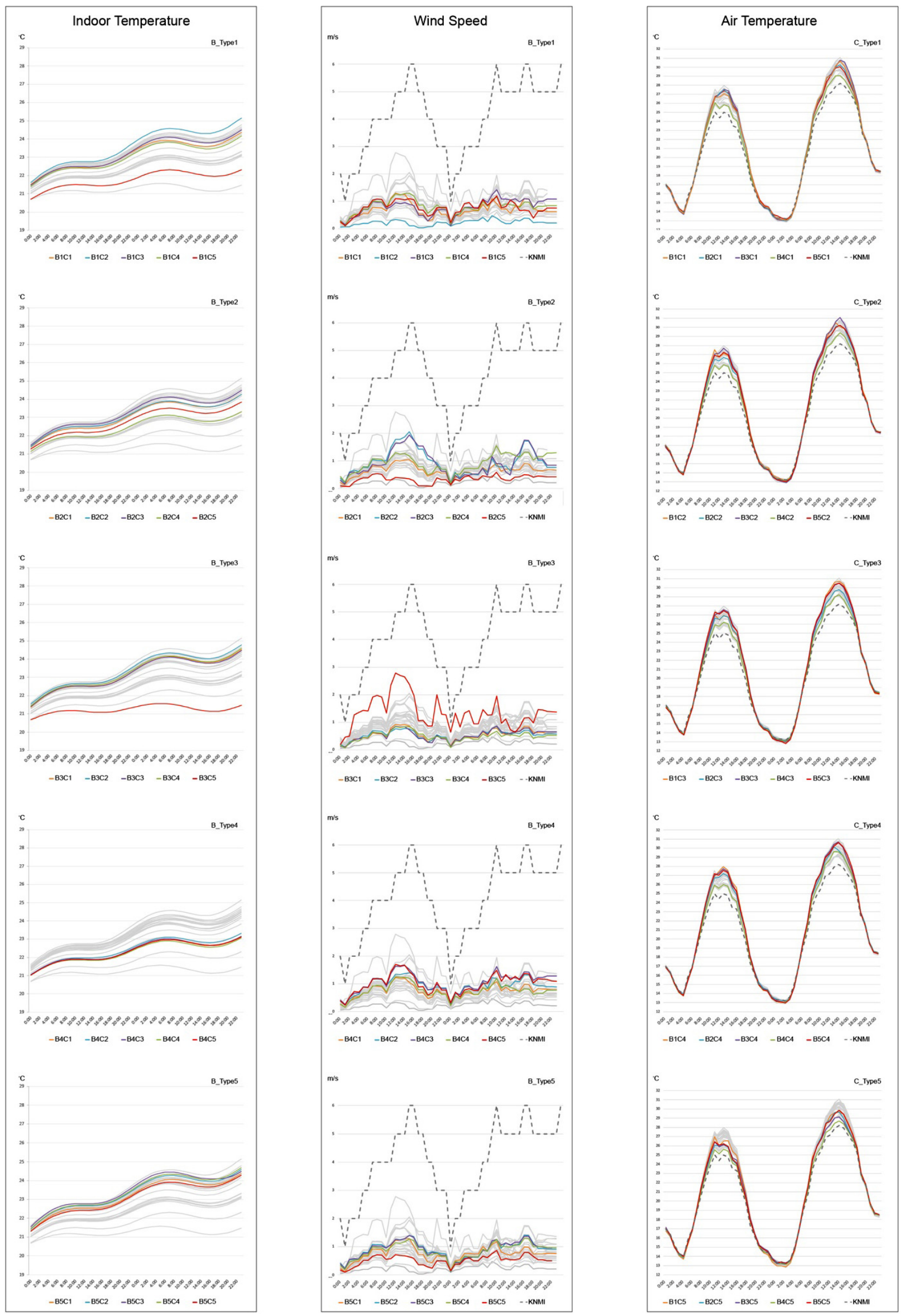

Figure 7. Indoor temperature values (left) and wind speed values (centre) for each building type; air temperature values for each context type (right). 
characteristics, since the study has the goal of isolating the microclimate impacts of morphological factors, all other modelling inputs-including material propertieswere kept constant. In order to limit the influence of this simplification on the results, in particular for buildings, a theoretical façade and roof material was created to represent average characteristics of absorption, reflection, and insulation capacity in the context. Windows were not included, therewith also limiting indoor heating due to incoming solar radiation. Finally, due to the computational limitations of the microclimatic model, simulations for an entire summer period were not possible. Instead, two consecutive days were selected as representative of a typical hot Dutch summer day without clouds.

\section{Conclusions}

Using a novel methodological approach for a data-driven classification of local climate typo-morphologies, a characterisation of five building types and five context types were defined for the Dutch case of the city of Rotterdam. The microclimate simulations carried out in ENVI-met for the resulting 25 combined archetypes showed that the identified types are able to describe a wide range of microclimate characteristics. The overall variations in air temperature, humidity, and wind for the 25 cases suggest that the morphological characteristics considered account for up to $2.5^{\circ} \mathrm{C}$ change in air temperature, up to $3 \mathrm{~m} / \mathrm{s}$ change in wind speed, and up to $5 \%$ change in relative humidity. Among all types, high-rise buildings (B_Type4) and high-density contexts (C_Type5) provide, respectively, the lowest indoor and outdoor temperatures during the days under study, showing the ability to mitigate the overheating process during the daytime in particular.

In addition, the analysis of climate patterns has confirmed similar behaviour among the cases representing each building type. The building type classification well represents patterns of indoor temperatures and wind velocities near façades. High-rise buildings (B_Type4) are characterised by the lowest indoor temperatures, while low-compact low-rise buildings (B_Type1) reach the highest indoor temperatures.

The analysis also highlights that some building types are more (or less) sensitive to the surrounding conditions than others. Due to different context conditions, midrise buildings with smaller footprint area (B_Type2) show large wind speed variations near the façade and probably as a consequence larger indoor temperature variation.

Regarding the context classification, no evident relation was found between context types and climate patterns within the groups. However, the flexibility granted by the clustering method allowed for a reading of microclimate patterns based on the hierarchical relations between groups. Two distinctive thermal patterns for medium (C_Type2) and high-density contexts (C_Type5) were found. However, very similar temperatures were observed in the three context types characterised by low building intensity and low building coverage (C_Type 1,3, and 4). Here, the use of the hierarchical clustering method showed that these three types are combined at a higher aggregation level in the dendrogram scheme. Therefore, it can be concluded that three types are enough to describe the morphological configurations of the context in relation to thermal behaviour.

The framework has allowed the authors to identify and climatically characterise building and context types in a Dutch case study. The application of the methodology in other geographical regions-or even other Dutch cities-might result in different morphological types and microclimate responses. Moreover, even if similar buildings and context types to the ones identified in Rotterdam would be found, the response of microclimate patterns and the intensity of UHI would likely change according to the meso-scale climate zone of the analysed city. Ultimately, the scope of the study is not to identify types that are present worldwide, but to offer an approach able to acknowledge the climate performance in conditions of spatial heterogeneity. The method proposed, when applied to other climate and spatial contexts, will contribute to the characterisation of local climate types, by recalling the concept of "locus" with its geographical, cultural, and atmospheric significance.

In the development of climate action plans, where tools are necessary to support the implementation of guidelines and climate adaptive interventions, this approach has the potential of supporting the understanding of the local spatial conditions that increase the risk of urban overheating. In the Netherlands, for example, national policy urged all local governments to perform such a risk assessment ("stress-test") and to formulate an implementation plan for climate adaptive measures before 2021 (National Delta Programme, 2015). However, currently, only $10 \%$ of the municipalities have set such an agenda for heat (National Delta Programme, 2021), indicating that local governments struggle to formulate appropriate measures. This is partly due to the fact that the existing infrastructure, urban fabric, and buildings limit the number of possible solutions and that there is a high variability of temperatures and related problems within the city (Albers et al., 2015). The identification of "archetypes" in each urban context can facilitate the planning of local, yet structural adaptation measures. For instance, in both new and existing urban developments, planners can regulate building type characteristics, being informed on the microclimatic trade-off that the existing context is likely going to create; and define the urgency of interventions based on the patterns of outdoor and indoor temperatures of types. Moreover, the result of this study has the potential to inform designers in integrating mitigation measures in existing contexts. In fact, the morphological characteristics of the types facilitate the understanding of the starting conditions and space availability on which designers are going to operate (for example, open and green space available, compactness of the urban fabric, etc.). 
Although the present approach is generally intended to support local governments in heat risk management, the conceptual instrument of climate types and the methodology presented for their definition is expected to facilitate the interaction between spatial, institutional, and technological components in a broader vision of smart sociotechnical governance (Jiang et al., 2020). From a technological perspective this approach supports the analysis of local climate phenomena, as well as the communication of complex climate mechanisms through the use of visually and semantically explained types. Such an approach is expected to facilitate a deeper understanding of climate change challenges in urban transformation processes and constitute a common base for the elaboration of innovative strategies and novel modes of governance. In this direction, the separate identification of building types and context types can support a more targeted identification of roles and responsibilities in heat risk management, helping the collaboration between private and public actors to increase the mitigative and adaptive capacity of local communities. Additionally, from a spatial perspective, the specificity of neighbourhoods and cities inherent in the method offers a framework on which communities can elaborate the integration of other pressing social, economic and environmental needs related to sustainability goals. However, the use of such an approach in transformation processes requires testing in real life settings. Additionally, the application of a microscale typological classification needs to be further explored, in combination with a meso-scale classification, to assess its potential in informing the implementation of mitigation and adaptation measures, more attuned to the specific location and configuration of the urban fabric. Moreover, supplementary studies are necessary to explore the influence of other climate-related parameters such as surface water cover, building materials and orientation, and to further validate and assess this approach by measurements.

\section{Acknowledgments}

The authors would like to thank A. A. A. Aldakheelallah, L. M. de Carvalho Filho, and Dr. D. Cannatella (Delft University of Technology) for their support during the data processing and visualisation. Finally, the authors would like to express their gratitude to the city of Rotterdam and the researchers in the "Klimaatmonitoring in de stad" project for providing spatial and measured climate data.

\section{Conflict of Interests}

The authors declare no conflict of interests.

\section{Supplementary Material}

Supplementary material for this article is available online in the format provided by the authors (unedited).

\section{References}

Ackerman, B. (1987). Climatology of Chicago area urbanrural differences in humidity. Journal of Applied Meteorology and Climatology, 26(3), 427-430. https://doi.org/10.1175/1520-0450(1987)026 $<0427$ :COCAUR>2.0.CO;2

Albers, R. A. W., Bosch, P. R., Blocken, B., van den Dobbelsteen, A. A. J. F., van Hove, L. W. A., Spit, T. J. M., van de Ven, F., van Hooff, T., \& Rovers, V. (2015). Overview of challenges and achievements in the climate adaptation of cities and in the Climate Proof Cities program. Building and Environment, 83, 1-10. https://doi.org/10.1016/j.buildenv.2014.09.006

Ali-Toudert, F., \& Mayer, H. (2006). Numerical study on the effects of aspect ratio and orientation of an urban street canyon on outdoor thermal comfort in hot and dry climate. Building and Environment, 41(2), 94-108. https://doi.org/10.1016/j.buildenv.2005.01.013

Allen-Dumas, M. R., Rose, A. N., New, J. R., Omitaomu, O. A., Yuan, J., Branstetter, M. L., Sylvester, L. M., Seals, M. B., Carvalhaes, T. M., Adams, M. B., Bhandari, M. S., Shrestha, S. S., Sanyal, J., Berres, A. S., Kolosna, C. P., Fu, K. S., \& Kahl, A. C. (2020). Impacts of the morphology of new neighborhoods on microclimate and building energy. Renewable and Sustainable Energy Reviews, 133, Article 110030. https:// doi.org/10.1016/j.rser.2020.110030

Amer, M., Mustafa, A., Teller, J., Attia, S., \& Reiter, S. (2017). A methodology to determine the potential of urban densification through roof stacking. Sustainable Cities and Society, 35, 677-691. https://doi.org/ 10.1016/j.scs.2017.09.021

Araldi, A., \& Fusco, G. (2019). From the street to the metropolitan region: Pedestrian perspective in urban fabric analysis. Environment and Planning B: Urban Analytics and City Science, 46(7), 1243-1263. https:// doi.org/10.1177/2399808319832612

Barthelemy, M. (2017). From paths to blocks: New measures for street patterns. Environment and Planning B: Urban Analytics and City Science, 44(2), 256-271. https://doi.org/10.1177/0265813515599982

Berghauser Pont, M., \& Haupt, P. (2010). Spacematrix: Space, density and urban form. NAi Publishers.

Berghauser Pont, M., Stavroulaki, G., Bobkova, E., Gil, J., Marcus, L., Olsson, J., \& Legeby, A. (2019). The spatial distribution and frequency of street, plot and building types across five European cities. Environment and Planning B: Urban Analytics and City Science, 46(7), 1226-1242. https://doi.org/10.1177/ 2399808319857450

Bibri, S. E., Krogstie, J., \& Kärrholm, M. (2020). Compact city planning and development: Emerging practices and strategies for achieving the goals of sustainability. Developments in the Built Environment, 4, Article 100021. https://doi.org/10.1016/j.dibe.2020. 100021

Bobkova, E. (2019). Towards a theory of natural occu- 
pation: Developing theoretical, methodological and empirical support for the relation between plot systems and urban processes [Doctoral dissertation, Chalmers University of Technology]. Chalmers University of Technology Repository. https://research. chalmers.se/en/publication/513622

Bobkova, E., Berghauser Pont, M., \& Marcus, L. (2021). Towards analytical typologies of plot systems: Quantitative profile of five European cities. Environment and Planning B: Urban Analytics and City Science, 48(4), 604-620. https://doi.org/10.1177/ 2399808319880902

Bourdic, L., Salat, S., \& Nowacki, C. (2012). Assessing cities: A new system of cross-scale spatial indicators. Building Research and Information, 40(5), 592-605. https://doi.org/10.1080/09613218.2012.703488

Bruse, M., \& Fleer, H. (1998). With a three dimensional numerical model. Environmental Modelling \& Software, 13(3/4), 373-384.

Caldera, M., Corgnati, S. P., \& Filippi, M. (2008). Energy demand for space heating through a statistical approach: Application to residential buildings. Energy and Buildings, 40(10), 1972-1983. https:// doi.org/10.1016/j.enbuild.2008.05.005

Chen, Yixing, Hong, T., Luo, X., \& Hooper, B. (2019). Development of city buildings dataset for urban building energy modeling. Energy and Buildings, 183, 252-265. https://doi.org/10.1016/j.enbuild.2018. 11.008

Chen, Yunhao, Wu, J., Yu, K., \& Wang, D. (2020). Evaluating the impact of the building density and height on the block surface temperature. Building and Environment, 168(19), Article 106493. https://doi.org/ 10.1016/j.buildenv.2019.106493

Crank, P. J., Sailor, D. J., Ban-Weiss, G., \& Taleghani, M. (2018). Evaluating the ENVI-met microscale model for suitability in analysis of targeted urban heat mitigation strategies. Urban Climate, 26, 188-197. https://doi.org/10.1016/j.uclim.2018.09.002

D'Acci, L. (2019). On urban morphology and mathematics. In L. D'Acci (Ed.), The mathematics of urban morphology (pp. 1-18). Birkhäuser.

Demetriou, D., See, L., \& Stillwell, J. (2013). A parcel shape index for use in land consolidation planning. Transactions in GIS, 17(6), 861-882. https://doi.org/ 10.1111/j.1467-9671.2012.01371.x

Duarte, D. H. S., Shinzato, P., dos Santos Gusson, C., \& Alves, C. A. (2015). The impact of vegetation on urban microclimate to counterbalance built density in a subtropical changing climate. Urban Climate, 14, 224-239. https://doi.org/10.1016/j.uclim.2015. 09.006

European Commission. (1991). Green paper on the urban environment-Communication from the Commission to the Council and the Parliament.

Forouzandeh, A. (2018). Numerical modeling validation for the microclimate thermal condition of semiclosed courtyard spaces between buildings. Sustain- able Cities and Society, 36, 327-345. https://doi.org/ 10.1016/j.scs.2017.07.025

Founda, D., Pierros, F., Katavoutas, G., \& Keramitsoglou, I. (2019). Observed trends in thermal stress at European cities with different background climates. Atmosphere, 10(8), Article 436. https://doi.org/10.3390/ atmos 10080436

Gemeente Rotterdam. (2018). Rotterdam in 3D. https:// www.rotterdam.nl/werken-leren/3d

Gil, J., Beirão, J. N., Montenegro, N., \& Duarte, J. P. (2012). On the discovery of urban typologies: Data mining the many dimansions of urban form. Urban Morphology, 16(1), 27-40. https://www. researchgate.net/publication/256895610_On_the_ discovery_of_urban_typologies_Data_mining_the_ many_dimensions_of_urban_form

Godoy-Shimizu, D., Steadman, P., Hamilton, I., Donn, M. Evans, S., Moreno, G., \& Shayesteh, H. (2018). Energy use and height in office buildings. Building Research and Information, 46(8), 845-863. https://doi.org/ 10.1080/09613218.2018.1479927

Grimmond, C. S. B., \& Oke, T. R. (1999). Aerodynamic properties of urban areas derived from analysis of surface form. Journal of Applied Meteorology, 38(9), 1262-1292.

Guerreiro, S. B., Dawson, R. J., Kilsby, C., Lewis, E., \& Ford, A. (2018). Future heat-waves, droughts and floods in 571 European cities. Environmental Research Letters, 13(3), Article 034009. https://doi.org/10.1088/17489326/aaaad3

Haggag, M. A., \& Ayad, H. M. (2002). The urban structural units method: A basis for evaluating environmental prospects for sustainable development. Urban Design International, 7(2), 97-108. https://doi.org/ 10.1057/palgrave.udi.9000071

Hausleitner, B., \& Berghauser Pont, M. (2017). Development of a configurational typology for microbusinesses integrating geometric and configurational variables. In Proceedings of the 11th International Space Syntax Symposium, (pp. 66.1-66.14). Instituto Superior Técnico.

Hecht, R., Meinel, G., \& Buchroithner, M. (2015). Automatic identification of building types based on topographic databases: A comparison of different data sources. International Journal of Cartography, 1(1), 18-31. https://doi.org/10.1080/23729333. 2015.1055644

Hoegh-Guldberg, O., Jacob, D., Taylor, M., Bindi, M., Brown, S., Camilloni, I., Diedhiou, A., Djalante, R., Ebi, K. L., Engelbrecht, F., Guiot, J., Hijioka, Y., Mehrotra, S., Payne, A., Seneviratne, S. I., Thomas, A., Warren, R., \& Zhou, G. (2018). Impacts of $1.5^{\circ} \mathrm{C}$ global warming on natural and human systems. In V. MassonDelmotte, P. Zhai, H.-O. Pörtner, D. Roberts, J. Skea, P. R. Shukla, A. Pirani, W. Moufouma-Okia, C. Péan, R. Pidcock, S. Connors, J. B. R. Matthews, Y. Chen, X. Zhou, M. I. Gomis, E. Lonnoy, T. Maycock, M. Tignor, \& T. Waterfield (Eds.), Global warming of $1.5^{\circ} \mathrm{C}$. An 
IPCC special report on the impacts of global warming of $1.5^{\circ} \mathrm{C}$ above pre-industrial levels and related global greenhouse gas emission pathways, in the context of strengthening the global response to the threat of climate change, sustainable development, and efforts to eradicate poverty (pp. 175-311).The Intergovernmental Panel on Climate Change.

Jiang, H., Geertman, S., \& Witte, P. (2020). Smart urban governance: An alternative to technocratic "smartness." GeoJournal. https://doi.org/10.1007/s10708020-10326-w

Jin, H., Cui, P., Wong, N., \& Ignatius, M. (2018). Assessing the effects of urban morphology parameters on microclimate in Singapore to control the urban heat island effect. Sustainability, 10(1), Article 206. https://doi.org/10.3390/su10010206

Jurelionis, A., \& Bouris, D. G. (2016). Impact of urban morphology on infiltration-induced building energy consumption. Energies, 9(3), 1-13. https://doi.org/ 10.3390/en9030177

Klok, L., Zwart, S., Verhagen, H., \& Mauri, E. (2012). The surface heat island of Rotterdam and its relationship with urban surface characteristics. Resources, Conservation and Recycling, 64, 23-29. https://doi.org/ 10.1016/j.resconrec.2012.01.009

Kong, F., Sun, C., Liu, F., Yin, H., Jiang, F., Pu, Y., Cavan, G., Skelhorn, C., Middel, A., \& Dronova, I. (2016). Energy saving potential of fragmented green spaces due to their temperature regulating ecosystem services in the summer. Applied Energy, 183, 1428-1440. https://doi.org/10.1016/j.apenergy.2016.09.070

Kong, L., Lau, K. K. L., Yuan, C., Chen, Y., Xu, Y., Ren, C., \& Ng, E. (2017). Regulation of outdoor thermal comfort by trees in Hong Kong. Sustainable Cities and Society, 31, 12-25. https://doi.org/10.1016/j.scs. 2017.01.018

Lan, Y., \& Zhan, Q. (2017). How do urban buildings impact summer air temperature? The effects of building configurations in space and time. Building and Environment, 125, 88-98. https://doi.org/10.1016/ j.buildenv.2017.08.046

Lenzholzer, S. (2015). Weather in the city: How design shapes urban climate. nai010.

Liu, W., You, H., \& Dou, J. (2009). Urban-rural humidity and temperature differences in the Beijing area. Theoretical and Applied Climatology, 96(3), 201-207. https://doi.org/10.1007/s00704-008-0024-6

Lobaccaro, G., \& Acero, J. A. (2015). Comparative analysis of green actions to improve outdoor thermal comfort inside typical urban street canyons. Urban Climate, 14, 251-267. https://doi.org/10.1016/j.uclim. 2015.10.002

Mangan, S. D., Koclar Oral, G., Erdemir Kocagil, I., \& Sozen, I. (2021). The impact of urban form on building energy and cost efficiency in temperate-humid zones. Journal of Building Engineering, 33, Article 101626. https://doi.org/10.1016/j.jobe.2020. 101626
Marique, A.-F., \& Reiter, S. (2014). Retrofitting the suburbs: Insulation, density, urban form and location. Environmental Management and Sustainable Development, 3(2), 138-153. https://doi.org/10.5296/ emsd.v3i2.6589

Mashhoodi, B., Stead, D., \& van Timmeren, A. (2020). Land surface temperature and households' energy consumption: Who is affected and where? Applied Geography, 114, Article 102125. https://doi.org/ 10.1016/j.apgeog.2019.102125

Mavrogianni, A., Wilkinson, P., Davies, M., Biddulph, P., \& Oikonomou, E. (2012). Building characteristics as determinants of propensity to high indoor summer temperatures in London dwellings. Building and Environment, 55, 117-130. https://doi.org/10.1016/ j.buildenv.2011.12.003

Morganti, M., Salvati, A., Coch, H., \& Cecere, C. (2017). Urban morphology indicators for solar energy analysis. Energy Procedia, 134, 807-814. https://doi.org/ 10.1016/j.egypro.2017.09.533

Næss, P., Saglie, I. L., \& Richardson, T. (2020). Urban sustainability: Is densification sufficient? European Planning Studies, 28(1), 146-165. https://doi.org/ 10.1080/09654313.2019.1604633

National Delta Programme. (2015). Delta Programme 2015-Working on the delta: The decisions to keep the Netherlands safe and liveable. https://english. deltacommissaris.nl/delta-programme/documents/ publications/2014/09/16/delta-programme-2015

National Delta Programme. (2021). Delta Programme 2021. Staying on track in climate-proofing the Netherlands (English version). https://english.delta programma.nl

Oke, T. R. (1987). Boundary layer climates. Routledge.

Oke, T. R., Johnson, G. T., Steyn, D. G., \& Watson, I. D. (1991). Simulation of surface urban heat islands under "ideal" conditions at night part 2: Diagnosis of causation. Boundary-Layer Meteorology, 56(4), 339-358. https://doi.org/10.1007/BF00119211

Peponis, J., Allen, D., French, S., Scoppa, M., \& Brown, J. (2007). Street connectivity and urban density: Spatial measures and their correlation. In Proceedings of the 6th International Space Syntax Symposium (pp. 4.01-4.12). Istanbul Technical University.

Perez, J., Fusco, G., Araldi, A., \& Fuse, T. (2018). Building typologies for urban fabric classification: Osaka and Marseille case studies [Conference paper]. International Conference on Spatial Analysis and Modeling, Tokyo, Japan.

Perini, K., \& Magliocco, A. (2014). Effects of vegetation, urban density, building height, and atmospheric conditions on local temperatures and thermal comfort. Urban Forestry and Urban Greening, 13(3), 495-506. https://doi.org/10.1016/j.ufug.2014.03.003

Rafiee, A., Dias, E., \& Koomen, E. (2016). Local impact of tree volume on nocturnal urban heat island: A case study in Amsterdam. Urban Forestry and Urban Greening, 16, 50-61. https://doi.org/10.1016/j.ufug. 
2016.01.008

Ratti, C., Baker, N., \& Steemers, K. (2005). Energy consumption and urban texture. Energy and Buildings. https://doi.org/10.1016/j.enbuild.2004.10.010

Rodríguez-Álvarez, J. (2016). Urban energy index for buildings (UEIB): A new method to evaluate the effect of urban form on buildings' energy demand. Landscape and Urban Planning, 148, 170-187. https:// doi.org/10.1016/j.landurbplan.2016.01.001

Roodenburg, J. (1983). Adaptation of rural minimum temperature forecasts to an urban environment. Archives for Meteorology, Geophysics, and Bioclimatology, Series B, 32(4), 395-401. https://doi.org/ 10.1007/BF02324659

Rui, L., Buccolieri, R., Gao, Z., Gatto, E., Rui, L., \& Ding, $W$. (2018). Study of the effect of green quantity and structure on thermal comfort and air quality in an urban-like residential district by ENVI-met modelling. Building Simulation, 12, 183-194. https://doi.org/ 10.1007/s12273-018-0498-9

Salat, S. (2009). Energy loads, $\mathrm{CO}_{2}$ emissions and building stocks: Morphologies, typologies, energy systems and behaviour. Building Research and Information, 37(5/6), 598-609. https://doi.org/10.1080/ 09613210903162126

Salata, F., Golasi, I., de Lieto Vollaro, R., \& de Lieto Vollaro, A. (2016). Urban microclimate and outdoor thermal comfort: A proper procedure to fit ENVI-met simulation outputs to experimental data. Sustainable Cities and Society, 26, 318-343. https://doi.org/10.1016/ j.scs.2016.07.005

Salvati, A., Monti, P., Coch Roura, H., \& Cecere, C. (2019). Climatic performance of urban textures: Analysis tools for a Mediterranean urban context. Energy and Buildings, 185, 162-179. https://doi.org/10.1016/ J.ENBUILD.2018.12.024

Salvati, A., Palme, M., Chiesa, G., \& Kolokotroni, M. (2020). Built form, urban climate and building energy modelling: Case-studies in Rome and Antofagasta. Journal of Building Performance Simulation, 13(2), 209-225. https://doi.org/10.1080/19401493. 2019.1707876

Saroglou, T., Meir, I. A., Theodosiou, T., \& Givoni, B. (2017). Towards energy efficient skyscrapers. Energy and Buildings, 149, 437-449. https://doi.org/ 10.1016/j.enbuild.2017.05.057

Serra, M., Gil, J., \& Pinho, P. (2017). Towards an understanding of morphogenesis in metropolitan streetnetworks. Environment and Planning B: Urban Analytics and City Science, 44(2), 272-293. https://doi. org/10.1177/0265813516684136

Serra, M., Psarra, S., \& O’Brien, J. (2018). Social and physical characterization of urban contexts: Techniques and methods for quantification, classification and purposive sampling. Urban Planning, 3(1), 58-74. https://doi.org/10.17645/up.v3i1.1269

Skelhorn, C., Lindley, S., \& Levermore, G. (2014). The impact of vegetation types on air and surface tem- peratures in a temperate city: A fine scale assessment in Manchester, UK. Landscape and Urban Planning, 121, 129-140. https://doi.org/10.1016/ j.landurbplan.2013.09.012

Smid, M., Russo, S., Costa, A. C., Granell, C., \& Pebesma, E. (2019). Ranking European capitals by exposure to heat waves and cold waves. Urban Climate, 27, 388-402. https://doi.org/10.1016/j.uclim.2018.12.010

Steeneveld, G. J., Koopmans, S., Heusinkveld, B. G., van Hove, L. W. A., \& Holtslag, A. A. M. (2011). Quantifying urban heat island effects and human comfort for cities of variable size and urban morphology in the Netherlands. Journal of Geophysical Research Atmospheres, 116(20), 1-14. https://doi. org/10.1029/2011JD015988

Stewart, I. D., \& Oke, T. R. (2012). Local climate zones for urban temperature studies. Bulletin of the American Meteorological Society, 93(12), 1879-1900. https:// doi.org/10.1175/bams-d-11-00019.1

Takebayashi, H. (2017). Influence of urban green area on air temperature of surrounding built-up area. Climate, 5(3), Article 60. https://doi.org/10.3390/ cli5030060

Tan, P.-N., Steinbach, M., \& Kumar, V. (2005). Introduction to data mining. Wesley Longman.

Terrin, J.-J. (2015). Villes et changement climatique. Ilots de chaleur urbains [Cities and climate change. Urban heat island]. Parentheses.

Toparlar, Y., Blocken, B., Maiheu, B., \& van Heijst, G. J. F. (2017). A review on the CFD analysis of urban microclimate. Renewable and Sustainable Energy Reviews, 80, 1613-1640. https://doi.org/10.1016/j.rser.2017. 05.248

Touchaei, A. G., \& Wang, Y. (2015). Characterizing urban heat island in Montreal (Canada)-Effect of urban morphology. Sustainable Cities and Society, 19, 395-402. https://doi.org/10.1016/j.scs.2015.03.005

Tsoka, S., Tsikaloudaki, A., \& Theodosiou, T. (2018). Analyzing the ENVI-met microclimate model's performance and assessing cool materials and urban vegetation applications-A review. Sustainable Cities and Society, 43, 55-76. https://doi.org/10.1016/j.scs. 2018.08.009

TU Delft. (2018). Plots weather stations Rotterdam. http://weather.tudelft.nl/plots/

van Hove, L. W. A., Jacobs, C. M. J., Heusinkveld, B. G., Elbers, J. A., Van Driel, B. L., \& Holtslag, A. A. M. (2015). Temporal and spatial variability of urban heat island and thermal comfort within the Rotterdam agglomeration. Building and Environment, 83, 91-103. https://doi.org/10.1016/j.buildenv.2014.08. 029

Vartholomaios, A. (2017). A parametric sensitivity analysis of the influence of urban form on domestic energy consumption for heating and cooling in a Mediterranean city. Sustainable Cities and Society, 28, 135-145. https://doi.org/10.1016/j.scs.2016.09. 006 
Vaz Monteiro, M., Doick, K. J., Handley, P., \& Peace, A. (2016). The impact of greenspace size on the extent of local nocturnal air temperature cooling in London. Urban Forestry and Urban Greening, 16, 160-169. https://doi.org/10.1016/j.ufug.2016.02.008

Vernez Moudon, A. (1997). Urban morphology as an emerging interdisciplinary field. Urban Morphology, 1(1), 3-10. https://doi.org/1027-4278

Wang, B., Cot, L. D., Adolphe, L., Geoffroy, S., \& Sun, S. (2017). Cross indicator analysis between wind energy potential and urban morphology. Renewable Energy, 113, 989-1006. https://doi.org/10.1016/ j.renene.2017.06.057

Ward, K., Lauf, S., Kleinschmit, B., \& Endlicher, W. (2016). Heat waves and urban heat islands in Europe: A review of relevant drivers. Science of the Total Environment, 569/570, 527-539. https://doi.org/ 10.1016/j.scitotenv.2016.06.119

Wei, R., Song, D., Wong, N. H., \& Martin, M. (2016). Impact of urban morphology parameters on microclimate. Procedia Engineering, 169, 142-149. https:// doi.org/10.1016/j.proeng.2016.10.017

Westerink, J., Haase, D., Bauer, A., Ravetz, J., Jarrige, F., \& Aalbers, C. B. E. M. (2013). Dealing with sustainability trade-offs of the compact city in periurban planning across European city regions. European Planning Studies, 21(4), 473-497. https://doi. org/10.1080/09654313.2012.722927
Willmott, C. J. (1982). Some comments on the evaluation of model performance. Bulletin of the American Meteorological Society, 63(11), 1309-1313. https://doi.org/10.1175/1520-0477(1982)063\%3c 1309:SCOTEO\%3e2.0.CO;2

Wolff, M., Haase, A., Haase, D., \& Kabisch, N. (2017). The impact of urban regrowth on the built environment. Urban Studies, 54(12), 2683-2700. https://doi.org/ $10.1177 / 0042098016658231$

Wu, Z., Dou, P., \& Chen, L. (2019). Comparative and combinative cooling effects of different spatial arrangements of buildings and trees on microclimate. Sustainable Cities and Society, 51, Article 101711. https://doi.org/10.1016/j.scs.2019.101711

Yang, X., Zhao, L., Bruse, M., \& Meng, Q. (2013). Evaluation of a microclimate model for predicting the thermal behavior of different ground surfaces. Building and Environment, 60, 93-104. https://doi.org/ 10.1016/j.buildenv.2012.11.008

Zhao, M., Cai, H., Qiao, Z., \& Xu, X. (2016). Influence of urban expansion on the urban heat island effect in Shanghai. International Journal of Geographical Information Science, 30(12), 2421-2441. https://doi. org/10.1080/13658816.2016.1178389

Zinzi, M., \& Santamouris, M. (2019). Introducing urban overheating: Progress on mitigation science and engineering applications. Climate, 7(1), Article 15. https://doi.org/10.3390/cli7010015

\section{About the Authors}
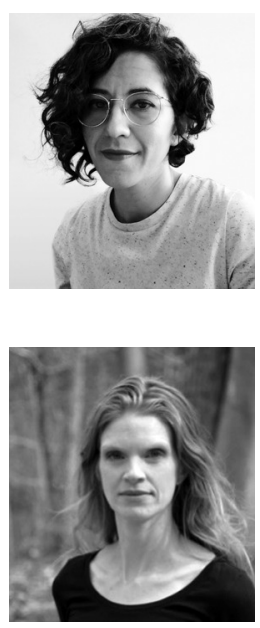

Marjolein Pijpers-van Esch is an Assistant Professor at the Department of Urbanism, Environmental Technology \& Design of the Faculty of Architecture and Built Environment at Delft University of Technology. She specialises in the impact of urban design on the urban microclimate on the scale levels of the street and neighbourhood. The foci of her research and teaching are design measures for climate adaptation, urban heat island (UHI) effect and outdoor thermal comfort, as well as the influence of the urban climate on the energy use of buildings.

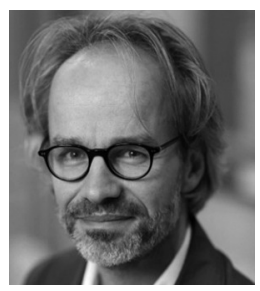

Arjan van Timmeren is a Full Professor at the Department of Urbanism, Environmental Technology \& Design of the Faculty of Architecture and the Built Environment at Delft University of Technology, and Principal Investigator at the AMS Institute in Amsterdam. His work focuses on sustainable development in the built environment, with emphasis on environmental technology, urban climate, urban metabolism, circular and biobased economy, and environmental behaviour. He leads several (inter)national projects and has seats in (inter)national steering groups, quality teams, and scientific boards. 